\title{
İndüktif Eşleşmiş Plazma-Kütle Spektrometresi ile Hypericum triquetrifolium Türünün Elementel Analizi
}

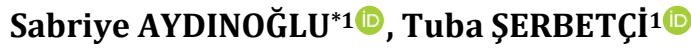 \\ ${ }^{1}$ Çukurova Üniversitesi, Eczacılık Fakültesi, Temel Bilimler Bölümü, 01330, Adana, Türkiye \\ ${ }^{2}$ Çukurova Üniversitesi, Eczacılık Fakültesi, Eczacılık Meslek Bilimler Bölümü, 01330, Adana, Türkiye
}

(Alınış / Received: 01.03.2021, Kabul / Accepted: 01.06.2021, Online Yayınlanma / Published Online: 25.12.2021)

\section{Anahtar Kelimeler} Hypericum triquetrifolium, Mikrodalga yakma, ICP-MS,

Ağır metal
Özet: Bu çalışmada Adana-Tarsus bölgesinden toplanan Hypericum triquetrifolium bitkisinin topraküstü kısımındaki metaller; kurşun( $\mathrm{Pb})$, civa(Hg), arsenik(As), selenyum(Se) ve yarı metaller; alüminyum $(\mathrm{Al})$, kadmiyum $(\mathrm{Cd})$ bakır $(\mathrm{Cu})$, demir $(\mathrm{Fe})$, nikel $(\mathrm{Ni})$, çinko $(\mathrm{Zn})$, kobalt $(\mathrm{Co})$, kalsiyum $(\mathrm{Ca})$, potasyum(K) içerikleri indüktif eşleşmiş plazma-kütle spektrometresi (ICP-MS) yöntemi ile incelenmiştir. Bitki numunesinin analize hazır hale getirilmesi aşamasında mikrodalga yakma yöntemi ile numuneler çözünür hale getirilmiştir. ICP-MS ölçümleri sonucunda, yüksek toksik özellik gösteren kadmiyum ve arsenik metallerine rastlanmazken, diğer yüksek toksik özellik gösteren ağır metal içerikleri; civa $\left(0,35 \pm 0,01 \mathrm{mg} \mathrm{kg}^{-1}\right)$ ve kurşun $\left(6,36 \pm 0,25 \mathrm{mg} \mathrm{kg}^{-1}\right)$ olarak belirlenmiștir. Elde edilen sonuçlar, bitki numunesinde toprak alkali metallerden kalsiyum $\left(1226,780 \pm 43,4 \mathrm{mg} \cdot \mathrm{kg}^{-1}\right)$ ve potasyum $(10308 \pm 103,7$ mg.kg-1) içeriklerinin oldukça yüksek oranda bulundukları tespit edilmiştir. Bitki içeriğinde analizi gerçekleştirilen diğer elementlerin miktarları; Se $\left(129,8 \pm 3,9 \mathrm{mg} \cdot \mathrm{kg}^{-1}\right)$ Al $\left(373,95 \pm 17,1 \mathrm{mg} \cdot \mathrm{kg}^{-1}\right), \mathrm{Cu}$ $(12,6 \pm 0.7$ mg.kg-1), Fe $(609,3 \pm 24,1$ mg.kg-1), Ni $(8,7 \pm 0,4$ mg.kg-1 $), \quad Z n(25,2 \pm 1,2$ mg.kg-1), Co $\left(0,08 \pm 0,01 \mathrm{mg} \cdot \mathrm{kg}^{-1}\right)$ olarak belirlenmiștir.

\section{Elemental Analysis of Hypericum triquetrifolium Species by Inductively Coupled Plasma Mass Spectrometry}

\section{Keywords}

Hypericum triquetrifolium, Microwave digestion, ICP-MS,

Heavy metal

\begin{abstract}
The aim of this study is to explore the presence and content of metals; lead(Pb), Mercury(Hg), arsenic(As), selenium(Se) and semi-metals; aluminium $(\mathrm{Al})$, cadmium $(\mathrm{Cd})$, copper $(\mathrm{Cu})$, iron $(\mathrm{Fe})$, nickel $(\mathrm{Ni})$, zinc $(\mathrm{Zn})$, Cobalt $(\mathrm{Co})$, calcium (Ca), potassium $(\mathrm{K})$ in aerial part of Hypericum triquetrifolium species collected from Adana-Tarsus by using inductively coupled plasma-mass spectrometry (ICP-MS) method. A convenient microwave technique has been used at the stage of preparing the plant sample for analysis. As a result of ICP-MS measurements, heavy metals with high toxicity such as mercury $(0.35 \pm 0.01 \mathrm{mg} . \mathrm{kg}$ $\left.{ }^{1}\right)$ and lead $\left(6.36 \pm 0.25 \mathrm{mg} \mathrm{kg}^{-1}\right)$, were determined, however other heavy metal such as arsenic and cadmium were not found in the plant sample. The results obtained showed that the alkaline earth metals, calcium $\left(1226.780 \pm 43.4 \mathrm{mg}^{\mathrm{kg}}{ }^{-1}\right)$ and potassium (10308 $\left.\pm 103.7 \mathrm{mg} \cdot \mathrm{kg}^{-1}\right)$ contents were found to be quite high in the plant sample. The amounts of other elements analyzed in the plant species were; Se $(129.8 \pm 3.9$ mg.kg-1) Al $(373.95 \pm 17.1$ mg.kg-1), Cu $(12.6 \pm 0.7$ mg.kg-1), $\mathrm{Fe}$ $\left(609.3 \pm 24.1 \quad \mathrm{mg} \cdot \mathrm{kg}^{-1}\right), \quad \mathrm{Ni}\left(8.7 \pm 0.4 \quad \mathrm{mg} \cdot \mathrm{kg}^{-1}\right), \quad \mathrm{Zn}\left(25.2 \pm 1.2 \quad \mathrm{mg} \cdot \mathrm{kg}^{-1}\right), \quad$ Co $\left(0.08 \pm 0.01 \mathrm{mg}^{\mathrm{kg}}{ }^{-1}\right)$,respectively.
\end{abstract}

\section{Giriș}

Tıbbi bitkiler kullanılarak hazırlanan bitkisel preparatların, hastalıkların önlenmesi ve tedavi edilmesi amacı ile toz drog ya da farklı farmasötik formlar halinde kullanımlarının son yıllarda gösterdiği artış göz önüne alındığında, bu ürünlerin halk sağlığı açısından güvenli olabilmeleri için belirli standartlara sahip olması aynı zamanda güvenlilik, kalite ve etkinliklerinin belirlenmesi gerekliliği ortaya çıkmaktadır [1]. Bitkisel ilaçların güvenliliğini doğrudan etkileyebilecek temel faktörlerden birisi de 
toprak, su ve havadan ağır metalleri kolaylıkla absorbe ederek kontamine olabilmeleridir. Yoğun trafiğin bulunduğu yol kenarları, şehir atıklarının depolandığı bölgeler ve atık sularının uzun süreli kullanımına sahip alanlara yakın alanda yetişen bitkilerde ağır metal oranlarının yüksek seviyelerde bulunduğu bildirilmiştir [2]. Bunun yanı sıra yağmurlar, atmosferdeki toz bulutları ve bitki koruma ajanlarının üretimde kullanılması sonucunda bu toksik elementlerin bitkilerde birikmesi söz konusudur [3].

Ağır metaller arasında özellikle civa, kurşun, arsenik ve kadmiyum toksik özelliktedir ve çok düşük konsantrasyonlarda mutajenik etki gösterirler [4, 5]. Tıbbi bitkilerin doğadan toplanıp preparat haline dönüştürülmesinden sonra, bitkilerde tutunan bu ağır metaller nihayet insan vücuduna girer ve santral sinir sistemi dahil olmak üzere karaciğer, akciğerler, kalp, böbrek ve hormonların normal işlevlerini bozarak hipertansiyon, karın ağrısı, deri döküntüleri, bağırsak ülseri ve farklı kanser türlerinde dahil pek çok ciddi sağlık problemine yol açabilirler [6]. Hypericum türleri, halk arasında yüzyıllardan bu yana şifa verici bir ot olarak sinir hastalıkları, adet krampları, siyatik, eklem iltihabı ve midevi rahatsızlıklardan kaynaklanan ağrıların giderilmesinde ve bazı cilt hastalıklarının tedavisinde kullanılmaktadır [7, 8]. Türkiye'de 106 takson ile temsil edilen Hypericum cinsine ait türler arasında tıbbi öneme sahip en yaygın tür olan $H$. perforatum üzerinde yürütülen çok sayıda preklinik ve klinik araştırma sonucu bitkinin topraküstü kısımlarının antidepresan, antiviral, antimikrobiyal, antitumoral, antienflamatuvar, antiülserojenik etkinliklerini bildirmektedir [9, 10]. Türkiye'de sarıkantaron adı ile bilinen bu türün halk arasında dahilen antispazmodik, yatıştırıcı ve kurt düşürücü olarak, haricen ise yara ve yanıkların tedavisinde yaygın olarak kullanıldığı kayıtlıdır [11]. Bununla birlikte Anadolu'da geniş yayllış gösteren $H$. triquetrifolium türünün de halk tıbbında cilt ve gastrointestinal hastalıkların tedavisinde kullanımı kayıtlıdır [12].

$\mathrm{Bu}$ çalışmanın amacl, Adana-Tarsus otoyolunu çevreleyen arazide doğal olarak yetişen $H$. triquetrifolium türünün topraküstü kısımlarının ağır metal içeriklerinin indüktif eşleşmiş plazma-kütle spektrometresi (ICP-MS) yöntemi ile analiz edilmesidir. Bilindiği gibi elementel analizde kullanılan en yaygın spektroskopik yöntemler, Alevli Atomik Absorpsiyon Spektrometresi (A-AAS), Grafit Firınlı Atomik Absorpsiyon Spektrofotometresi(GFAAS), İndüktif eşleşmiş plazma-kütle spektrometresi (ICP-MS) ve Induktif Eşleşmiş Plazma Emisyon Spektrometresidir (ICP-OES) [13, 14]. Elementel analizde uygulanacak yöntemin seçiminde belirleyici olan en önemli parametre analizi yapılacak olan numunedeki elementlerin derişim seviyeleridir. ICPMS yöntemi birçok element için ppb seviyesinden daha düşük derişimdeki tayin sınırına sahip olması, geniş doğrusal aralık sağlaması, aynı örnekte çoklu elementel analiz imkânı sağlaması, daha küçük numune miktarlarında çalışmaya olanak sağlaması ve güvenirliği açısından ağır metallerin ve eser elementlerin analizinde yaygın olarak kullanılmaktadır [13, 15-19].

Elementel analizde kullanılacak yöntemin seçimiyle birlikte numunenin analize hazır hale getirilmesi için uygulanacak çözünürleştirme basamağı da elde edilen sonuçların doğruluğu açısından önem tașımaktadır [20]. Bitki preparatlarının elementel analize hazırlanması aşamasında yaygın olarak; yaş yakma, kuru yakma ve mikrodalga yakma yöntemleri kullanılmaktadır. Son yıllarda, yapılan çalışmalarda mikrodalga yakma yöntemi, diğer yakma proseslerine göre uçucu türlerden dolayı madde kaybının az olması, daha hızlı, kolay ve tekrarlanabilirliğinin yüksek olması gibi avantajlara sahip olması açısından daha çok tercih edilmektedir[13, 15, 16, 21, 22]. Farklı bölgelerden toplanan $H$. triquetrifolium bitki örneğindeki ağır metal analizine ilişkin önceki çalışmalarda yaş yakma, kuru yakma yöntemleriyle kullanılmış olup, mikro dalga yönteminin uygulandığı bir çalışma söz konusu olmamaktadır. Ek olarak önceki çalışmalarda kullanılan analiz yöntemleri; AAAS, GF-AAS ve ICP-OES olmaktadır. Bu çalışmada, $H$. triquetrifolium bitkisinin toz haline getirilen toprak üstü kısımlarının mikrodalga yöntemiyle analize hazır hale getirilmesinin ardından, ppb seviyesinin altında tayin sınırına sahip olan ICP-MS yöntemi kullanılarak ağır metal içeriği belirlenmiştir.

\section{Materyal ve Metot}

\subsection{Materyal}

Çalışma da materyal olarak, Adana-Tarsus otoyolunu çevreleyen arazide doğal olarak yetişen $H$. triquetrifolium (Çukurova Üniversitesi Eczacılık Fakültesi Herbaryumu, CUEF1699, Haziran 2020) bitkisinin toprak üstü kısmındaki ağır metallerin ve eser elementlerin miktarları analiz edilmiștir. Analizi yapılan tüm elementlerin standart çözeltileri Perkin Elmer Multi ICP-MS standart solution, $1000 \mu \mathrm{g} / \mathrm{ml}$ kullanılarak \%2'lik $\mathrm{HNO}_{3}$ çözeltisi içerisinde hazırlanmıștır. Tüm çözeltilerin hazırlanmaları sırasında Elga (Option Q7) ultrasaf su kullanılarak elde edilen ultra saf su kullanılmıştır.

\section{2. Örneklerin hazırlanması}

Çalışmada bitki numunesinin elementel analize hazırlanmasında mikro dalga yakmalı parçalama tekniği kullanılmıştır.

\subsection{Metot}

Kurutulup toz haline getirilen homojen bitki numunesinden 3 eşit miktarda 0.1 gramlık 
numuneler tartılarak, mikrodalga yakma cihazının (Berghof, Speedwave Xpert) teflon yakma kaplarına konulmuş ve sırasıyla üzerine $5 \mathrm{~mL} \mathrm{HNO}_{3}$ ve $3.0 \mathrm{~mL}$ $\mathrm{H}_{2} \mathrm{O}_{2}$ çözeltileri eklenerek karıştırılmıştır. Karıştırma işlemi bittikten sonra 10 dakika beklenilip yakma kaplarının ağzı kapatılarak Tablo 1.'de verilen sıcaklık programı uygulanmıştır.

Tablo 1. Mikro dalga isıtmalı yakma işleminde bitki numunelerinde uygulanan sıcaklık programı

\begin{tabular}{cccc}
\hline Basamak & $\mathrm{T}\left({ }^{\circ} \mathrm{C}\right)$ & $\mathrm{P}($ bar $)$ & Zaman(Dakika) \\
\hline 1 & 150 & 30 & 5 \\
2 & 190 & 35 & 10 \\
3 & 50 & 14 & 15 \\
\hline
\end{tabular}

\section{Bulgular}

H. triquetrifolium bitkisinin toprak üstü kısmının ICPMS yöntemiyle analizi sonucunda saptanan ağır metal içerikleri sonuçların \% bağll standart sapma (\%BSS) değerleri ile birlikte Tablo 2'de verilmektedir.

Tablo 2. Hypericum triquetrifolium için saptanan ağır metal içerikleri $(\mathrm{n}=3)$

\begin{tabular}{ccc}
\hline Element & mg.kg-1 & \%BSS \\
\hline $\mathrm{Al}$ & $374,0 \pm 17,0$ & 4,6 \\
$\mathrm{Cd}$ & ${ }^{-1} \mathrm{LD}$ & - \\
$\mathrm{Cu}$ & $12,6 \pm 0,6$ & 5,3 \\
$\mathrm{Fe}$ & $609,3 \pm 24,1$ & 4,0 \\
$\mathrm{Ni}$ & $8,7 \pm 0,4$ & 4,4 \\
$\mathrm{Zn}$ & $25,2 \pm 1,3$ & 5,0 \\
$\mathrm{Co}$ & $0,08 \pm 0,01$ & 11,4 \\
$\mathrm{Ca}$ & $1226,780 \pm 43$ & 3,5 \\
$\mathrm{~K}$ & $10308,0 \pm 104,0$ & 1,0 \\
$\mathrm{Se}$ & 129,8 & 3,0 \\
$\mathrm{As}$ & $* \mathrm{LOD}$ & - \\
$\mathrm{Hg}$ & $0,35 \pm 0,01$ & 3,9 \\
$\mathrm{~Pb}$ & $6,4 \pm 0,3$ & 4,0 \\
\hline
\end{tabular}

*LOD: Tespit limitinin altında

Elde edilen sonuçlar incelendiğinde, bulunan metal içeriklerinin Dünya Sağlık Örgütü verilerine göre kabul edilebilir aralıkta olduğu gözlenmiştir [23].

\section{Tartışma ve Sonuç}

DSÖ verilerine göre dünya nüfusunun \%80'inin birinci basamak tedavide bitkisel preparatları tedavi amaçlı kullanmaktadır. Bitkisel preparat kullanımındaki artışın yanı sıra preparatların terapötik etkilerinin kimyasal bileşimleri ile ilişkili olması, tıbbi amaçla kullanılan bitkisel türlerin elementel analizini gerekli kılmaktadır. Daha önce aynı türe ait farklı bölgelerden toplanan örnekler ile yapılan çalışmalar ile türe ait metal içerikleri analiz edilmiştir [24,25,26]. Elde edilen sonuçlara göre Güney Doğu Anadolu bölgesinden (Diyarbakır) toplanan $H$. triquetrifolium örneklerinde arsenik $\left(0,31 \pm 0,02 \mathrm{mg} \cdot \mathrm{kg}^{-1}\right)$ ve kadmiyum $\left(0,07 \pm 0,005 \mathrm{mg} \cdot \mathrm{kg}^{-}\right.$ $\left.{ }^{1}\right)$ ağır metallerinin tespit edilmesine karşılık ICP-MS yöntemi ile analiz edilen numunede bu ağır metallere rastlanmamıştır. Mevcut araştırmada 373,953 $\pm 17,1$ mg.kg-1 olarak bulunan $\mathrm{Al}$ içeriği aynı tür için

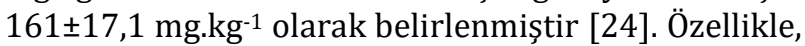
alüminyum miktarının bitki numunesinin yetiștiği toprağın asiditesine bağlı olup, asidik topraklardan pasif düfizyonla bitkiye geçerek genç yapraklarda toplandığı bilinmektedir [27]. Tablo 2.'de görüldüğü gibi makro elementlerden sırasıyla $\mathrm{K}$ ve Ca yüksek miktarlarda bulunmuştur. Daha önce yapılan çalışmalarda $H$. triquetrifolium türleri yaş yakma prosesi ve FAAS yöntemi kullanarak, $\mathrm{K}$ içeriğini için çalışmadaki sonuçlarla uyumlu olarak 820-1100 mg.kg-1 olarak belirlerken, Ca miktarı daha az olarak 100-500 mg.kg-1 Aralığında belirlemişlerdir [24]. Türkiye'nin batı bölgesinden (İzmir) toplanan örneklerden, elde edilen bitki ekstrelerindeki yaş yakma prosesini takip eden FAAS yöntemi kullanılarak gerçekleştirilen analiz sonucunda Ca miktarını, 433 mg.kg-1 olarak bildirmişlerdir [28]. Yaptı̆̆ımız çalışmada mikro elementlerin bulunma miktarları $\mathrm{Ni}<\mathrm{Cu}(12,6$ mg.kg-1) $<\mathrm{Zn}<\mathrm{Se}<$ Fe olarak tespit edilmiştir. Önceki çalışmalarda, $\mathrm{Cu}$ miktarı, FAAS ile benzer olarak farklı Hypericum triquetrifolium 13-17 mg.kg-1 [26] olarak bulunmuşken, ICP-OES tekniği ile 6 mg.kg-1 [24] olarak belirlenmiștir. Tablo 2.'de elde edilen sonuçlardan $\mathrm{Ni}$ içeriğine bakıldığ literatürdeki aynı tür için elde edilen değerler GF-AAS ile 0,5 mg.kg-1 ve ICP-OES tekniği ile 1,2 mg.kg-1 olmak üzere bu çalışmadaki sonuçlardan oldukça düşük sonuçlar elde edilmiştir [24, 26]. Aynı şekilde, yaş yakma ve FAAS yöntemiyle Fe içeriği 125 mg.kg-1 [24] olarak tayin edilirken; bu çalışmada uygulanan analiz ve yakma yöntemleriyle 603,9 mg.kg-1 olarak bulunmuştur. Analiz edilen ağır metallerden $\mathrm{Pb}$ miktarı $(6,39$ mg.kg-1), literatürdeki yaș yakma ve ICP-OES tekniği ile aynı tür için 0,39 mg. $\mathrm{kg}^{-1}$ değerine klyasla oldukça yüksek miktarda bulunmuş, literatürde bu tür için $\mathrm{Hg}$ analize yönelik herhangi bir çalışmaya rastlanmadığı için herhangi bir kıyaslama yapılamamıştır [24].

Türkiye'nin kuzey kesimindeki endüstriyel alanda topladıkları, Hypericum perforatum L. türü için yaş yakma ve FAAS yöntemi kullanılarak yaptıkları elementel analizlerde ortalama değerleri, $\mathrm{Cu}$ için 6,3 mg.kg-1 ; Fe için 434,3 mg.kg-1; Zn elementini 68,3 mg.kg-1 ve $\mathrm{Pb}$ ağır metal içeriğini 47,5 mg.kg-1 olarak vermişlerdir [25]. Çalışmada belirtilen metal içeriklerinin örneklerin toplandığı bölgelere bağlı olarak geniş aralıkta sonuçlar elde etmişlerdir.

Yaptığımız çalışmada elde edilen metal içeriklerinin diğer çalışmalar ile kıyaslandığında öncelikle bitki numunelerinin toplandığı bölgelerdeki gerek toprak yapısı, trafik yoğunluğu ve endüstriyel yapıya bağlı olarak değişiklik gösterdiği, aynı zamanda kullanılan analiz yöntemi ve numune hazırlama yöntemine de bağlı olduğu sonucuna varılmıştır. Elde edilen sonuçlardan yola çıkarak daha hızlı ve numunedeki uçucu bileşenlerin kaybını engelleyen mikrodalga 
ısıtmalı numune hazırlama yönteminin ve ppb seviyesinin altında analiz imkânı sağlayan ICP-MS yönteminin Hypericum triquetrifolium bitkisinin elementel analizi için uygun olduğu sonucuna varılmıştır.

Yapılan çalışmada Hypericum perforatum türüne benzerliğinden ötürü kantaron olarak halk arasında tıbbi kullanımı kayıtlı olan Hypericum triquetrifolium bitkisinin toprak üstü kısımlarından hazırlanan numunenin elementel içeriği incelenmiş, insan vücudundaki birçok metabolik reaksiyon için gerekli olan $\mathrm{Ca}$ ve $\mathrm{K}$ elementlerince zengin olduğu, ağır metallerden As ve $\mathrm{Cd}$ içermediği belirlenmiştir. Çalışmada türün taşıdığı ağır metal ve eser element miktarlarının dünya sağlık örgütünün kabul ettiği aralıkta olduğu belirlenmiştir [23].

Yapılan çalışmanın Adana bölgesinde yetişen Hypericum triquetrifolium türüne ait daha önce yapılan bir çalışma olmaması açısından literatüre ve daha sonra ki yapılacak çalışmalara katkıda bulunacağı düşünülmektedir.

\section{Teşekkür}

Bitki materyalinin Çukurova Üniversitesi Eczacılık Fakültesi Herbaryumunda saklanması ve numaralandırılması konusunda yardımlarından ötürü Doç. Dr. Serpil Demirci Kayıran'a teșekkür ederiz.

\section{Etik Beyanı}

Bu çalışmada, "Yükseköğretim Kurumları Bilimsel Araștırma ve Yayın Etiği Yönergesi" kapsamında uyulması gerekli tüm kurallara uyulduğunu, bahsi geçen yönergenin "Bilimsel Araștırma ve Yayın Etiğine Aykırı Eylemler" başlığı altında belirtilen eylemlerden hiçbirinin gerçekleștirilmediğini taahhüt ederiz.

\section{Kaynakça}

[1] Folashade, K. O., Omoregie, E. H., Ohogu, A. P. 2012. Standardization of Herbal Medicines - A Review. International Journal of Biodiversity and Conservation, 4(3), 101-112.

[2] Türkyılmaz, A., Sevik, H., Çetin, M., Saleh, E. A. 2018. Changes in Heavy Metal Accumulation Depending on Traffic Density in Some Landscape. Plants. Polish Journal of Environmental Studies, 27(5), 2277-2284.

[3] Maobe, M. A. G., Gatebe, E., Gitu, L., Rotich, H. 2012. Profile of heavy metals in selected medicinal plants used for the treatment of diabetes, malaria and pneumonia in Kisii region, Southwest Kenya. Global Journal of Pharmacology, 6(3), 245-251.

[4] Kakosy, T., Hudak, A., Naray, M. 1996. Lead Intoxication Epidemic Caused by Ingestion of
Contaminated Ground Paprika. Journal of Toxicology: Clinical Toxicology, 34(5), 507-511.

[5] Sathiavelu, A., Gajalakshmi, S., Iswarya, V., Ashwini, R., Divya, G., Mythili, S. 2012. Evaluation of heavy metals in medicinal plants growing in Vellore District. European Journal of Experimental Biology, 2(5), 14571461.

[6] Haider, S., Naithani, V., Barthwal , J., Kakkar, P. 2004. Heavy Metal Content in Some Therapeutically İmportant Medicinal Plants. Bulletin of Environmental Contamination and Toxicology, 72(1), 119-127.

[7] Çırak, C., Kurt, D., 2014. Önemli Tıbbi Bitkiler Olarak Hypericum Türleri. ANADOLU journal of the Aegean Agricultural Research Institute, 24(1), 42-58.

[8] Kaçar, O., Azkan, N. 2010. Tıbbi bitki olarak sarı kantaron (Hypericum perforatum L.) ve halk sağlığındaki yeri. Dünya Gıda Dergisi, 82-89.

[9] Barnes, J., Anderson, L. A., Phillipson, J. D. 2001. St John's wort (Hypericum perforatum L.): review of its chemistry, pharmacology and clinical properties. Journal of Pharmacy and Pharmacology. 53: 583-600.

[10] Baytop, T. 1999. Türkiye'de Bitkiler ile Tedavi, Geçmiste ve Bugün. Nobel Tıp Kitabevleri, II. Baskı ISBN: 975-420-021- 1. İstanbul, 480s.

[11] Başköse İ., Savran A. 2018. A new species from southern Anatolia (Dedegöl Mountain Series Çürük Mountain) in Turkey: Hypericum bilgehanbilgilii (Hypericaceae). Phytotaxa. 374(2), 110-118.

[12] Çırak, C., Radusiene, J., Janulis, V., Ivanauskas, L., Çamaş, N., Ayan, A. K. 2011. Phenolic constituents of Hypericum triquetrifolium Turra (Guttiferae) growing in Turkey: variation among populations and plant parts. Turkish Journal of Biology, 35, 449-456.

[13] Tokalioglu, S. 2012. Determination of trace elements in commonly consumed medicinal herbs by ICP-MS and multivariate analysis. Food Chemistry, 134(4), 2504-2508.

[14] Bulska, E., Ruszczyńska, A. 2017. Analytical Techniques for Trace Element Determination. Physical Sciences Reviews, 20178002.

[15] Yang, F. Y., Jiangab S. J., Sahayam A. C. 2014. Combined use of HPLC-ICP-MS and microwaveassisted extraction for the determination of cobalt compounds in nutritive supplements. Food Chemistry, 147, 215-219.

[16] Kılıç, S. 2018. Comparison of mineral element amounts of aromatic plant and their oils. Gida, 43(4), 617-623. 
[17] Sumontha Nookabkaew, S., Rangkadilok, N., Satayavivad, J. 2006. Determination of Trace Elements in Herbal Tea Products and Their Infusions Consumed in Thailand. Journal of Agricultural and Food Chemistry, 54, 69396944.

[18] Avula, B., Wang, Y., Smillie, T. J., Aydin, N .S., Khan, I. 2010. Quantitative Determination of Multiple Elements in Botanicals and Dietary Supplements Using ICP-MS. Journal of Agricultural and Food Chemistry, 58, 88878894.

[19] Zhao, X., Wei, J., Shu, X., Kong, W., Yang, M. 2016. Multi-elements determination in medical and edible Alpinia oxyphylla and Morinda officinalis and their decoctions by ICP-MS. Chemosphere, 164, 430-435.

[20] Queralt, I., Ovejero, M., Carvalho L., Marques A. F., Llabres J. M. 2005. Quantitative determination of essential and trace element content of medicinal plants and their infusionsby XRF and ICP techniques. X-Ray Spectrometry, 34, 213-217.

[21] Bizzi, C. A., Nóbrega, J. A. , Barin, J. S. , Oliveira, J. S. S. , Schmidt, L. , Mello, P. A., Flores, E. M. M. 2014. Effect of simultaneous cooling on microwave-assisted wet digestion of biological samples with diluted nitric acid and $\mathrm{O}_{2}$ pressure. Analytica Chimica Acta, 837, 16-22.

[22] Kilic, S., Soylak, M. 2020. Determination of trace element contaminants in herbal teas using ICPMS by different sample preparation method. Journal of Food Science and Technology, 57, 927-933.

[23] World Health Organization. Quality Control Methods for Medicinal Plant Materials, WHO Offset Publication. WHO Geneva, 1998.

[24] Yener, I. 2019. Trace Element Analysis in Some Plants Species by Inductively Coupled Plasma Optical Emission Spectrometry (ICP-OES). Jist, 9(3), 1492-1502.

[25] Ayan, A. A., Kizilkaya, R., Cirak, C., Kevseroglu, K. 2006. Heavy Metal Contents of St. John's wort (Hypericum perforatum L.) Growing in Northern Turkey. Journal of Plant Sciences, 1(3), 182-186.

[26] Gomez, M. R., Ceutti, S., Olsina R. A., Silva, M. F., Martinez, L. D. 2004. Metal content monitoring in Hypericum perforatum pharmaceutical derivatives by atomic absorption and emission spectrometry. Journal of Pharmaceutical and Biomedical Analysis, 34: 569-576.

[27] Hayacibara, F. M., Queiroz, C. S., Tabchouryand, C. P. M., Cury, J. A. 2004. Fluoride and aluminum in teas and tea-based beverages. Revista de Saúde Pública, 38(1), 100-105.

[28] Elgin Cebe, G., Sogut, O. 2018. Calcium and Magnesium Contents in Three Hypericum L. Species from Turkey. Journal of Medicinal Food, 8, 819-822. 